\title{
0 emprego da análise de balanços e métodos estatísticos na área pública: o ranking de gestão dos municípios catarinenses*
}

\author{
Maurélio Soares** \\ Ricardo Luiz Wüst Corrêa de Lyra*** \\ Nelson Hein**** \\ Adriana Kroenke*****
}

SumÁrio: 1. Introdução; 2. Referencial teórico; 3. Metodologia e procedimentos de pesquisa; 4. Apresentação e análise de resultados; 5. Considerações finais.

Summary: 1. Introduction; 2 . Theoretical references; 3 . Research methodology; 4. Data description and analysis; 5 . Conclusion.

Palavras-chave: contabilidade pública; análise de balanços; gestão pública.

KEY WORDS: public accounts; balance sheet analysis; public management.

Com o fenômeno da globalização, a contabilidade tem passado por modificações que se refletiram, inicialmente, no âmbito empresarial e só alguns anos mais tarde na administração pública. Há uma tendência cada vez maior e crescente de pressionar

\footnotetext{
* Artigo recebido em set. 2010 e aceito em out. 2010.

** Mestre em ciências contábeis pela Universidade Regional de Blumenau (PPGCC/FURB). Endereço: rua Antônio da Veiga, 140, sala D 202 - Victor Konder - CEP 89012-900, CP 1.507, Blumenau, SC, Brasil. E-mail: maurelio.14@hotmail.com.

*** Doutor em controladoria e contabilidade pela FEA da Universidade de São Paulo (USP). Professor do Programa de Pós-Graduação em Ciências Contábeis da Universidade Regional de Blumenau (PPGCC/FURB). Endereço: rua Antônio da Veiga, 140, sala D 202 - Victor Konder _ CEP 89012-900, CP 1.507, Blumenau, SC, Brasil. E-mail: lyra@furb.br.

**** Pós-doutorado em modelos analíticos e de simulação pelo Instituto Nacional de Matemática Pura e Aplicada (Impa). Professor do Programa de Pós-Graduação em Ciências Contábeis da Universidade Regional de Blumenau (PPGCC/FURB). Endereço: rua Antônio da Veiga, 140, sala D 202 — Victor Konder - CEP 89012-900, CP 1.507, Blumenau, SC, Brasil. E-mail: hein@furb.br. ***** Mestre em ciências contábeis pela Universidade Regional de Blumenau (PPGCC/FURB). Endereço: rua Antônio da Veiga, 140, sala D 202 — Victor Konder - CEP 89012-900, CP 1.507, Blumenau, SC, Brasil. E-mail: didlen@terra.com.br.
} 
os governantes para ampliarem o campo de suas responsabilidades financeiras a partir da contabilidade voltada para a gestão das contas públicas. A responsabilidade fiscal dos governos é fundamental para fomentar o crescimento econômico e o desenvolvimento dos municípios. O presente estudo visa demonstrar em que medida os índices de análise econômico-financeira podem ser empregados na administração pública a fim de se estabelecer um ranking na gestão dos municípios catarinenses. Para atingir tal finalidade, utilizou-se de conceitos e técnicas de análise de balanço, os quais foram tratados com a aplicação da análise de componentes principais. Os resultados indicam a importância do emprego da análise de balanços na área pública como ferramenta a ser utilizada no cotidiano da administração governamental.

The application of balance sheet analysis and statistical methods in public sector: the ranking of management of municipalities from Santa Catarina

With the phenomenon of globalization, accounting has undergone changes which were reflected initially in the business and only a few years later in public administration. There is a growing trend and increasing pressure on governments to broaden the scope of its financial responsibilities from the accounting-oriented management of public accounts. Fiscal responsibility of governments is crucial for fostering economic growth and development of municipalities. This study aims to demonstrate how rates of economic and financial analysis can be employed in public administration in order to establish a ranking in the management of municipalities of Santa Catarina. To achieve this purpose, was used the concepts and techniques of balance analysis, which were treated with the application of main components' analysis. The results indicate the importance of using the balance analysis in the public sector as a tool to be used in daily government administration.

\section{Introdução}

A administração pública municipal, executora das políticas públicas locais que demandam maior proximidade com a população, é responsável pela arrecadação de tributos e sua devolução à sociedade por meio de bens e serviços públicos, e dessa forma atende os interesses comuns da população.

A contabilidade das instituições públicas pode ser entendida como ramo da contabilidade geral, em que aparece legalmente a figura do orçamento público, que estima receitas e fixas despesas, planejando suas ações por meio do Plano Plurianual, da Lei de Diretrizes Orçamentárias e da Lei Orçamentária.

Um grande diferencial do ramo da contabilidade privada para o ramo da contabilidade pública é que, enquanto na área privada pode-se fazer tudo que a lei não proíbe, na pública permite-se realizar somente aquilo que a lei determina (Meirelles, 2000). 
A escrituração contábil da área pública, até pouco tempo atrás, resumia-se no cumprimento legal dos demonstrativos exigidos pela Lei Federal no 4.320/1964. A partir da promulgação da Lei de Responsabilidade Fiscal (Lei Complementar no 101/2000) iniciou-se um marco definitivo no caminho da transparência, no equilíbrio fiscal e na moralização da atividade pública brasileira. Esta lei alterou definitivamente o comportamento dos administradores públicos quanto à forma de gerirem o patrimônio da coisa pública.

Nos estudos acadêmicos em contabilidade pública, verifica-se que há certa escassez de material ou estudos quando se fala em "análise de balanço", diferentemente do que ocorre na área privada.

Segundo Andrade (2002:297), “diversas formas podem ser utilizadas para efetuar uma análise de balanço, considerando a técnica contábil propriamente dita, assim como a utilização de quocientes na busca de utilizar determinada conta contábil em relação a um parâmetro de interesse do gestor".

Com a vigência da LRF, alguns parâmetros foram criados para definir limites de aplicações de despesas em relação à receita, os quais passaram a ser ferramentas obrigatórias de análise, visando em primeira mão ao cumprimento da legalidade, assim como da gerência e do controle.

A obtenção de um índice ou quociente, por mais simples que signifique a relação entre dois dados, torna-se importante à medida que se pretende extrair determinada informação e, como consequência, tomar-se a melhor decisão na aplicação de recursos públicos.

Nesta perspectiva, a questão de pesquisa central deste trabalho é: utilizando-se das técnicas de análise de balanços é possível estabelecer um ranking de gestão dos municípios catarinenses?

Diante do exposto, o presente estudo tem por objetivo demonstrar em que medida os índices de análise econômico-financeira podem ser empregados na administração pública a fim de se estabelecer um ranking na gestão dos municípios catarinenses.

A pesquisa justifica-se pela importância em se utilizar ferramentas de análise de balanço, que auxiliem a gestão pública responsável na busca por economicidade, eficiência e equilíbrio das contas públicas, bem como o estabelecimento de um ranking na gestão dos municípios catarinenses.

O artigo está estruturado em cinco tópicos, iniciando com a introdução do tema proposto. Em seguida perfaz-se uma incursão teórica contextualizando a contabilidade pública no Brasil, as demonstrações contábeis governamentais, a Lei de Responsabilidade Fiscal e a gestão das contas públicas. Após a descrição da metodologia empregada, segue a análise dos dados partindo-se do emprego do método estatístico aplicado, o que possibilita 
estabelecer o ranking proposto no presente estudo. Por último apresentamse as considerações finais.

\section{Referencial téorico}

\subsection{A contabilidade pública}

Até recentemente, vários estudiosos apresentavam definições conceituais para a contabilidade pública ou governamental. Para Angélico (1990:113), "é a disciplina que aplica, na administração pública, as técnicas de registros e apurações contábeis em harmonia com as normas gerais do Direito Financeiro".

Segundo Kohama (2000:50), "é o ramo da contabilidade que estuda, orienta, controla e demonstra a organização e execução da Fazenda Pública, o patrimônio público e suas variações".

Já para Silva (2004:196), "é uma especialização da contabilidade ciência, voltada para o estudo e a análise dos atos e fatos que ocorrem na Administração Pública".

Todos esses conceitos são válidos e apresentam visões peculiares para cada autor, dando ênfase à técnica, ao registro, à demonstração e à análise da contabilidade dos órgãos governamentais.

Uma definição oficial emergiu recentemente no Conselho Federal de Contabilidade (CFC), por meio da NBC T 16, em que o objeto da contabilidade pública é o patrimônio da entidade pública. Este ramo da contabilidade possui normas e técnicas próprias de contabilidade que são aplicadas por todos os entes que recebam, guardem, apliquem ou movimentem recursos públicos.

A mesma norma relata que, como ramo da ciência contábil, a contabilidade pública aplica, no processo gerador de informações, os princípios e as normas contábeis direcionados à gestão patrimonial de entidades públicas. Oferece aos usuários informações sobre os resultados alcançados e os aspectos de natureza orçamentária, econômica, financeira e física do patrimônio da entidade e suas mutações, em apoio ao processo de tomada de decisão e à adequada prestação de contas.

Portanto, estuda o patrimônio dos órgãos e entidades da administração pública, o orçamento e os atos praticados pelo administrador público que, potencialmente, possam alterar qualitativa ou quantitativamente o patrimônio, buscando munir de informações o processo decisório de gestores públicos e prestar contas à sociedade sobre a aplicação dos recursos arrecadados.

Importante destacar um breve relato da origem e do desenvolvimento da contabilidade pública no país. 
De acordo com Slomski (2003), no Brasil, as primeiras tratativas visando à implantação de um sistema de contabilidade pública datam de 1808, com a criação do Erário Régio pelo então imperador dom João VI. Seguiramse algumas décadas de retrocesso especialmente a partir de 1850, quando a contabilidade pública tornou-se inoperante e foi praticamente esquecida, o que motivou a recusa da Inglaterra em conceder um empréstimo ao Brasil, em 1914, por falta de documentação contábil do tesouro brasileiro.

Formou-se então uma Comissão para organizar os serviços de contabilidade do Tesouro e, em 1922, foi editado o Decreto ํo 4.536, de 28 de janeiro 1922, aprovando o Código de Contabilidade, e o Decreto no 15.783 , de 8 de novembro de 1922, instituindo o Regulamento Geral de Contabilidade Pública (Slomski, 2003).

Posteriormente, editou-se a Lei no 4.320, de 17 de março de 1964, que estatui normas de direito financeiro para a elaboração e o controle dos orçamentos e do patrimônio da União, estados e municípios, que é, atualmente, o grande marco regulatório da contabilidade pública no Brasil.

Até meados da década de 1980, as finanças públicas brasileiras padeciam de grave desorganização estrutural, inexistindo instrumentos adequados de planejamento, execução e controle financeiro. As fortes pressões à época, em busca de um ajuste fiscal, criaram as condições necessárias à organização e à produção de um sistema de informações gerenciais. Criou-se, em 1986, a Secretaria do Tesouro Nacional (STN), órgão central do Sistema de Contabilidade do Poder Executivo, e, em 1987, o Sistema Integrado de Administração Financeira do Governo Federal (Siafi).

Em 2000, instituiu-se a Lei Complementar no 101, conhecida como a Lei de Responsabilidade Fiscal (LRF), que estabeleceu normas voltadas à responsabilidade na gestão fiscal, buscando uma melhor transparência das contas públicas e a qualidade na aplicação dos recursos públicos.

Na prática, contudo, a contabilidade pública no Brasil ainda se move de acordo com regras defasadas no tempo, de caráter extremamente legalista e carente de premente mudança. As últimas atualizações vêm sendo realizadas pela STN, que é o órgão responsável pela emissão de normas de consolidação das contas públicas e de padronização das prestações de contas.

\subsection{Demonstrações contábeis na área pública}

A contabilidade pública tem como meta captar, acumular, registrar e interpretar fenômenos que afetam a situação orçamentária, financeira e patrimonial 
das entidades que a compõem, e por meio das demonstrações contábeis tornase possível apurar o patrimônio da entidade.

Atualmente, as demonstrações contábeis vêm passando por um processo de convergência das normas internacionais do setor público, visando suprir uma carência existente na elaboração destas demonstrações, que até então tinham utilizado, por analogia, alguns métodos adotados pelo setor privado.

Além do Balanço Orçamentário, Balanço Financeiro, Balanço Patrimonial e das Demonstrações das Variações Patrimoniais, as demonstrações contábeis da área pública convergidas no padrão internacional incluirão, a partir de 2010, a Demonstração do Fluxo de Caixa, a Demonstração do Resultado Econômico e as Notas Explicativas (Resolução CFC no $1.133 / 2008$ ).

Segundo a NBC T 16.1, as demonstrações contábeis de cada exercício financeiro devem ser acompanhadas por anexos, outros demonstrativos exigidos por lei e pelas notas explicativas, bem como serão extraídas dos livros, registros e documentos que compõem o sistema contábil da entidade.

As demonstrações contábeis devem ser publicadas com a identificação da entidade pública e com a assinatura da autoridade responsável e do contabilista da entidade registrado no Conselho Regional de Contabilidade. A publicidade, em cada exercício financeiro, será realizada com a apresentação dos valores correspondentes ao exercício anterior (CFC, 2008).

O principal objetivo da divulgação das demonstrações contábeis em cada exercício financeiro é o ato de colocar à disposição da sociedade as informações contábeis da entidade, e, a partir delas, extrair os dados necessários para atingir o objetivo proposto nesse estudo.

\subsection{A LRF e a gestão das contas públicas}

Visando implementar um novo mecanismo de auxílio às instituições orçamentárias, promover a disciplina fiscal nos entes federados e controlar o endividamento público, criou-se a Lei de Responsabilidade Fiscal (LRF).

A LRF é um código de conduta para os administradores públicos que passaram a obedecer a normas e limites para administrar finanças, prestar contas de quanto e como gastam os recursos públicos.

A importância do surgimento da LRF e seus efeitos imediatos nas contas públicas são reconhecidos por Pires (1999:3), ao afirmar que

[...] o sucesso da Lei de Responsabilidade Fiscal e esta, por sua vez, pode oferecer um ingrediente extremamente importante para fazer deslanchar as experi- 
ências participativas na gestão pública: transparência nos dados e informações, prestação de contas, gerenciamento eficiente de recursos.

Esta Lei é parte de um conjunto de medidas de políticas econômicas adotadas nas três esferas de governo, estando sustentada por certos princípios de gestão que, a partir de sua entrada em vigor, implantaram uma nova mentalidade da gestão fiscal para a administração pública brasileira, e é sustentada por quatro pilares básicos: o planejamento, a eficiência, o controle e a transparência (TCE/SC, 2001).

O planejamento é condição prévia para a execução das ações governamentais na busca do atendimento das necessidades sociais, mantendo-se o equilíbrio das contas públicas no processo de execução orçamentária.

A LRF enfatiza sua principal finalidade em seu artigo $1^{\circ}$ ao estabelecer "normas de finanças públicas voltadas à responsabilidade na gestão fiscal", cujo objetivo é controlar o avanço do endividamento com a fixação de regras, limites e postura gerencial.

Para Matias-Pereira (2006:297), a LRF visa a "aumentar a qualidade das ações de gestão fiscal dos recursos públicos confiados aos agentes da administração pública de todas as esferas de governo e coibir os abusos que provocam danos ou prejuízos ao patrimônio público".

A busca pela eficiência refere-se ao atendimento das metas planejadas com qualidade. Caso sua administração seja eficiente nas ações governamentais, com o equilíbrio das contas públicas, a otimização dos recursos, aliados à satisfação do usuário, é sinal de que o gestor obteve sucesso em sua administração.

De acordo com Filho (2008), os controles, tanto interno como externo na administração pública, buscam oferecer maior segurança para o gestor público, pois buscam evitar e apontar erros, apurar eventuais desvios ou uso indevido do dinheiro público, e servem como ferramenta que traga segurança e qualidade na tomada de decisão.

Torna-se nítida a percepção de que, a partir da edição da LRF, o administrador público passe a ter seu foco de atuação voltado para uma gestão pública responsável que, de acordo com Nascimento (2006:177), apresenta os seguintes postulados:

、 prevenção de riscos e correção de desvios que afetem o equilíbrio das contas públicas;

v garantia de equilíbrio nas contas, via cumprimento de metas de resultados entre receitas e despesas; 
V ação planejada e transparente.

Além de ser uma exigência legal, a transparência, a publicação dos relatórios contábeis e a prestação de contas são mecanismos por meio dos quais os gestores demonstraram seu desempenho nos negócios públicos, pois este, via de regra, é o maior interessado nessa forma de apresentação de contas.

Corroborando com essa ideia, Slomski (2003:167) afirma que "[...] na administração pública, é, certamente, onde mais deve estar presente a filosofia da accountability (dever de prestar contas), pois, quando a sociedade elege seus representantes, espera que os mesmos ajam em seu nome, de forma correta, e que prestem contas de seus atos".

Nesse sentido, as demonstrações contábeis do setor público assumem papel de relevante importância, não apenas pela imperiosidade da lei, mas também como instrumento de gestão pública.

\subsection{Análise de balanços}

A contabilidade não se resume apenas ao registro de fatos contábeis, tendo como função a busca das causas e dos efeitos que esses fatos causam sobre o patrimônio da entidade.

Analisando as demonstrações resultantes da escrituração contábil, decomponda-os em partes segmentadas, será possível fornecer os subsídios para melhor interpretação e absorção de informações para seus componentes (Andrade, 2002).

O principal objetivo da análise de balanços é o de formar uma ideia sobre o desempenho de uma entidade durante um determinado período, bem como obter informações que auxiliem de forma complementar a outras projeções sobre o futuro da entidade estudada (Martins, 2005).

A utilização de índices na análise de balanços, seja na área pública, seja na privada, envolve a aplicação de cálculos de quocientes que relacionam um conjunto de valores expressos nas demonstrações contábeis.

Importante destacar o conceito de balanço considerado por Kohama (1991:245): "Balanço é a apuração da situação de determinado patrimônio, em determinado instante, representada, sinteticamente, num quadro de duas seções: Ativo e Passivo. É também entendido como a igualdade de duas somas, de uma conta ou de um quadro".

Ao tratarmos de análise e interpretação de balanços públicos, deve-se destacar que os dados serão obtidos de quatro peças que fazem parte do con- 
junto denominado de balanços públicos: Orçamentário, Financeiro, Patrimonial e as Demonstrações das Variações Patrimoniais.

Ressalta-se que além de se utilizar dos resultados apresentados nas demonstrações contábeis, a análise de balanços poderá envolver outras informações úteis nesse trabalho. Esse entendimento está contido na Lei no 4.320 em seu art. 85:

Os serviços de contabilidade serão organizados de forma a permitir o acompanhamento da execução orçamentária, o conhecimento da composição patrimonial, a determinação dos custos dos serviços industriais, o levantamento dos balanços gerais, a análise e a interpretação dos resultados econômicos e financeiros.

Com a vigência da LRF, alguns parâmetros foram criados para definir limites de despesas em relação às receitas, os quais se tornaram essenciais como ferramentas de análise, visando primeiramente o cumprimento da legalidade, como os gastos com pessoal e educação, e como instrumento de gestão e controle.

\section{Metodologia e procedimentos da pesquisa}

\subsection{Características da pesquisa}

A pesquisa tem características de cunho descritivo, com abordagem quantitativa e corte seccional. A pesquisa descritiva, de acordo com Gil (1995), possui como objetivo principal descrever as características de determinada população ou fenômeno, ou o estabelecimento de relações entre as variáveis.

A população da pesquisa compreende os 293 municípios do estado de Santa Catarina. Os dados foram obtidos junto aos sites da Secretaria do Tesouro Nacional (STN), Instituto Brasileiro de Geografia e Estatística (IBGE) e do Tribunal de Contas do Estado de Santa Catarina (TCE/SC).

No que tange à coleta de dados, para a formação da análise dos índices utilizaram-se como base os dados relativos ao exercício financeiro de 2007 dos municípios catarinenses, caracterizando esse estudo como de corte seccional (cross-sectional).

Optou-se pelo ano de 2007 por não ser ano de eleições municipais, e por se tratar do terceiro ano de mandato da gestão 2005-08, sugerindo que o 
administrador público já conheça bem o funcionamento da máquina pública e atue com um orçamento planejado por seu próprio governo.

Babbie (1999) descreve-o como investigação de algum fenômeno no qual se realiza um corte transversal no tempo, onde são feitas análises detalhadas, para fundamentar as observações realizadas uma única vez.

O tratamento e a análise de dados serão realizados por meio de um software aplicativo do tipo científico (Statistical Package for Social Science - SPSS), que possibilite aplicar técnicas estatísticas complexas utilizadas em ciências sociais, visando estabelecer um ranking na gestão dos municípios catarinenses.

$\mathrm{Na}$ presente pesquisa optou-se por utilizar o modelo matemático da análise de componentes principais, o qual busca uma forma de explicar a estrutura de variância-covariância dos dados que se está analisando.

Richardson (1999:70) caracteriza a abordagem quantitativa "pelo emprego de quantificação tanto nas modalidades de coleta de informações, quanto no tratamento destas por meio de técnicas estatísticas, desde as mais simples, como percentual, média, desvio-padrão, às mais complexas, como coeficientes de correlação, análise de regressão etc.”.

As limitações do presente estudo referem-se ao emprego de uma ferramenta estatística para apenas um período de administração dos municípios, sugerindo que este ranking possa ser alterado quando aplicada em outros períodos de análise.

\section{2 Índices para análise de balanços}

Optou-se pela escolha de índices usualmente empregados para a análise econômico-financeira das empresas, tendo os mesmos sido obtidos mediante pesquisa bibliográfica entre os autores que tratam do assunto no país.

Apesar da diversidade de índices disponíveis para emprego em análise de balanço, utilizaram-se aqueles que são passíveis de obtenção e análise de dados afins dos balanços públicos. Nesse sentido, Matarazzo (1998:157) afirma que "o importante não é o cálculo de grande número de índices, mas de um conjunto de índices que permita conhecer a situação da empresa, segundo o grau de profundidade desejada da análise".

A partir dessa constatação, o quadro 1 apresenta os índices utilizados no presente estudo e a sua respectiva indicação para interpretação. 


\section{Quadro 1 \\ Quadro-resumo dos índices}

\begin{tabular}{|c|c|c|c|c|}
\hline Variável & Índice & Fórmula & Interpretação & Fonte \\
\hline$P_{1}$ & $\begin{array}{l}\text { Liquidez Corrente } \\
\text { (LC) }\end{array}$ & $\begin{array}{l}\text { Ativo Financeiro/ } \\
\text { Passivo Financeiro }\end{array}$ & $\begin{array}{l}\text { (quanto MAIOR } \\
\text { melhor) }\end{array}$ & $\begin{array}{l}\text { Balanço Patrimonial } \\
\text { Anexo } 14 \text { (Lei nº- } \\
4.320 / 1964)\end{array}$ \\
\hline$P_{2}$ & $\begin{array}{l}\text { Liquidez Imediata } \\
\text { (LI) }\end{array}$ & $\begin{array}{l}\text { Disponibilidade + Recursos } \\
\text { Vinculados/Passivo } \\
\text { Financeiro }\end{array}$ & $\begin{array}{l}\text { (quanto MAIOR } \\
\text { melhor) }\end{array}$ & $\begin{array}{l}\text { Balanço Patrimonial } \\
\text { Anexo } 14 \text { (Lei } \mathrm{n}^{\circ} \\
\text { 4.320/1964) }\end{array}$ \\
\hline$P_{3}$ & $\begin{array}{l}\text { Situação Financeira } \\
\text { Líquida (SL) }\end{array}$ & $\begin{array}{l}\text { Ativo Financeiro - Passivo } \\
\text { Financeiro/Receita Total }\end{array}$ & $\begin{array}{l}\text { (quanto MAIOR } \\
\text { melhor) }\end{array}$ & $\begin{array}{c}\text { Balanço Patrimonial } \\
\text { e Demonstração das } \\
\text { Variações Patrimoniais } \\
\text { Anexos } 14 \text { e } 15 \text { (Lei no } \\
4.320 / 1964)\end{array}$ \\
\hline$P_{4}$ & $\begin{array}{l}\text { Comprometimento } \\
\text { com Dívidas (CD) }\end{array}$ & $\begin{array}{l}\text { Amortização da dívida/ } \\
\text { Receita Corrente Líquida }\end{array}$ & $\begin{array}{l}\text { (quanto } \\
\text { MENOR } \\
\text { melhor) }\end{array}$ & $\begin{array}{c}\text { Demonstração das } \\
\text { Variações Patrimoniais } \\
\text { Anexo 15 (Lei no } \\
4.320 / 1964) \text { e } \\
\text { Anexo III - RREO } \\
\text { (LC 101/2000) }\end{array}$ \\
\hline$P_{5}$ & $\begin{array}{l}\text { Grau de } \\
\text { Dependência } \\
\text { (GD) }\end{array}$ & $\begin{array}{l}\text { Receita de Transferências/ } \\
\text { Receita Total }\end{array}$ & $\begin{array}{l}\text { (quanto } \\
\text { MENOR } \\
\text { melhor) }\end{array}$ & $\begin{array}{c}\text { Balanço Financeiro } \\
\text { Anexo } 13 \text { (Lei no } \\
4.320 / 1964)\end{array}$ \\
\hline$P_{6}$ & $\begin{array}{l}\text { Estrutura de } \\
\text { Capital (EC) }\end{array}$ & $\begin{array}{l}\text { Passivo Financeiro + } \\
\text { Passivo Permanente (ELP)/ } \\
\text { Ativo Total }\end{array}$ & $\begin{array}{l}\text { (quanto } \\
\text { MENOR } \\
\text { melhor) }\end{array}$ & $\begin{array}{c}\text { Balanço Patrimonial } \\
\text { Anexo } 14 \text { (Lei nº } \\
\text { 4.320/1964) }\end{array}$ \\
\hline$P_{7}$ & $\begin{array}{l}\text { Despesas com } \\
\text { Educação (DE) }\end{array}$ & $\begin{array}{l}\text { Gastos com Educação/ } \\
\text { Receita de Impostos }\end{array}$ & $\begin{array}{l}\text { (quanto MAIOR } \\
\text { melhor) }\end{array}$ & $\begin{array}{l}\text { Anexo X - RREO } \\
(\text { LC 101/2000) }\end{array}$ \\
\hline$P_{8}$ & $\begin{array}{l}\text { Despesas com } \\
\text { Pessoal (DP) }\end{array}$ & $\begin{array}{l}\text { Despesas com Pessoal + } \\
\text { Encargos/Receita Corrente } \\
\text { Líquida }\end{array}$ & $\begin{array}{l}\text { (quanto } \\
\text { MENOR } \\
\text { melhor) }\end{array}$ & $\begin{array}{l}\text { Anexo I-RGF } \\
(\text { LC 101/2000) }\end{array}$ \\
\hline
\end{tabular}

Fonte: Elaborado pelo autor.

O índice de liquidez corrente (LC) revela a parcela das obrigações que a disponibilidade de recursos próprios pode saldar, evitando a utilização de recursos de terceiros de curto e longo prazo para financiar as políticas públicas.

Já o índice de liquidez imediata (LI) determina a relação de quanto a instituição possui de disponibilidade imediata ou de alta liquidez para cada unidade de obrigação exigível no passivo financeiro. Os recursos vinculados referem-se aos provenientes de convênios e programas cuja aplicação está comprometida com um programa de ação de governo (ex.: recursos para programa da saúde). 
Já o índice de situação líquida financeira (SL) demonstra qual é a relação entre a diferença do montante do ativo financeiro, subtraído do passivo financeiro, em relação à receita total.

Assim, os índices $\mathrm{P}_{1}, \mathrm{P}_{2}$ e $\mathrm{P}_{3}$ medem a solidez, ou base financeira do município, que demonstrará a existência de condições para o pagamento ou assunção de novas dívidas.

$\mathrm{O}$ índice de comprometimento com dívidas (GD) demonstra a representatividade dos encargos com a amortização da dívida interna/externa em relação à receita corrente líquida. Quanto maior essa relação, menos recursos sobram para manutenção e expansão dos serviços públicos.

O índice de grau de dependência (GD) evidencia o grau de dependência da administração municipal em relação a recursos de outras esferas governamentais. Este indicador é construído sob a hipótese de que as transferências influenciam negativamente o desempenho fiscal dos governos receptores, expresso pelo baixo esforço fiscal e/ou pela expansão dos gastos públicos desses governos, ocasionando maior endividamento.

O índice estrutura de capital (EC) indica o montante de capital de terceiros que está sendo utilizado pela administração pública para exercer suas funções revelando as decisões relacionadas às fontes de financiamento das políticas públicas.

Os quocientes $\mathrm{P}_{4}, \mathrm{P}_{5}$ e $\mathrm{P}_{6}$ mostram as grandes linhas de decisões financeiras para os investimentos públicos, quer seja para a obtenção ou para aplicação de recursos.

$\mathrm{O}$ índice despesas com educação (DE), ou $\mathrm{P}_{7}$, criado recentemente pela LRF, indica o percentual de recursos investidos pela entidade na educação. Tal índice vem ao encontro do cumprimento do mandamento constitucional que versa sobre a aplicação de, no mínimo, $25 \%$ da receita de impostos. Trata-se de um mandamento constitucional que leva o administrador público a gastar (investir) em educação um percentual mínimo, garantindo assim o direito essencial do cidadão à educação.

E, por fim, o índice de despesas com pessoal (DP), ou $\mathrm{P}_{8}$ indica a parcela da receita corrente comprometida com despesas de pessoal. Esta é uma variável que mostra a rigidez orçamentária dos municípios e espera-se que tenha uma relação positiva com o endividamento municipal sob o pressuposto de que maior dispêndio com pessoal, maior é o grau de endividamento dos municípios, visto que, em princípio, municípios que destinam grande parte de suas receitas para o pagamento de pessoal tendem a reduzir os recursos disponíveis para utilização em outras áreas. De acordo com a LRF, os municípios podem aplicar até o limite de $60 \%$ da receita corrente líquida.

Infere-se que a aplicação de análise de índices depende intrinsecamente da pergunta que deve ser respondida pelo resultado do índice, do objetivo que 
se busca atingir, neste caso, o estabelecimento de um ranking da gestão nos municípios catarinenses.

\section{Apresentação e análise de resultados}

\subsection{Modelo matemático não linear multivariável}

A análise multivariada trata de mensurações do grau de associação, ou grau de correlação, entre variáveis aleatórias. Variáveis aleatórias são definidas como aquelas que seguem as leis do acaso.

$\mathrm{Na}$ presente pesquisa optou-se por utilizar o modelo matemático da análise de componentes principais, o qual busca uma forma de explicar a estrutura de variância-covariância dos dados que se está analisando, ou seja, do vetor aleatório analisado.

De acordo com Maroco (2003:231), análise de componentes principais "é uma técnica de análise exploratória que transforma um conjunto de variáveis correlacionadas num conjunto menor de variáveis independentes, combinações lineares das variáveis originais, designadas por componentes principais".

O modelo é assim expresso:

$$
\begin{aligned}
& \xi_{1}=\gamma_{11} \chi_{1}+\gamma_{12} \chi_{2}+\ldots+\gamma_{1 \rho} \chi_{\rho} \\
& \xi_{2}=\gamma_{21} \chi_{1}+\gamma_{22} \chi_{2}+\ldots+\gamma_{2 \rho} \chi_{\rho} \\
& \xi_{\rho}=\gamma_{\rho 1} \chi_{1}+\gamma_{\rho 2} \chi_{2}+\ldots+\gamma_{\rho \rho} \chi_{\rho}
\end{aligned}
$$

Segundo Luchesa (2004:38), as componentes principais "constituem um novo conjunto de variáveis, obtido através da rotação rígida dos eixos originais, na direção em que se obtém a máxima variabilidade dos dados, mantendo-se, assim, exatamente a mesma relação original entre eles".

Portanto, a partir de um conjunto de dados com $p$ variáveis serão obtidas $p$ componentes principais. Porém, identificam-se as componentes mais importantes na estrutura de variância-covariância.

Observa-se, portanto, que, em geral, após a maximização da variabilidade produzida pela rotação dos eixos no espaço, $R^{p}$, um número menor de componentes principais consegue explicar mais claramente a estrutura de variância-covariância do que a estrutura primária dos dados originais.

A este respeito, informa Chaves Neto (apud Luchesa, 2004:16), que “embora $p$ componentes sejam necessárias para reproduzir a variabilidade total do sistema, frequentemente muito desta variabilidade pode ser explicada por um número pequeno de componentes principais". 
Dessa forma, maximizando a variabilidade dos dados, obtém-se uma descrição mais simples e, ao mesmo tempo, mais clara, da estrutura de variância-covariância e, com frequência, torna-se possível tecer ilações e identificar relacionamentos que, em geral, não seriam possíveis com as coordenadas originais das variáveis.

Assim, os objetivos da análise dos componentes principais situam-se em reduzir o tamanho da matriz de dados e facilitar sua interpretação.

\section{1 Estabelecimento do ranking}

A partir da análise da matriz de variância-covariância das variáveis escolhidas para a análise, o método apresentou o melhor número de componentes principais, combinações lineares das variáveis escolhidas, as quais foram utilizadas conforme a tabela.

Ressalta-se que, para ajustar a covariância, os dados passaram pelo processo de normalização, o que impossibilita ocorrência de erros ou desequilíbro na análise estatística.

Tabela

Matriz de componentes principais

\begin{tabular}{|cccc|}
\hline \multirow{2}{*}{ Variável } & \multicolumn{3}{c|}{ Componente redimensionada } \\
\cline { 2 - 4 } & 1 & 2 & 3 \\
\hline$P_{1}$ & $-0,007$ & 0,122 & $-0,056$ \\
$P_{2}$ & 0,009 & 0,121 & $-0,050$ \\
$P_{3}$ & $-0,580$ & 0,151 & $-0,053$ \\
$P_{4}$ & 0,863 & 0,023 & $-0,043$ \\
$P_{5}$ & $-0,793$ & $-0,109$ & $-0,175$ \\
$P_{5}$ & 0,441 & 0,141 & $-0,103$ \\
$P_{7}$ & 0,026 & $-0,228$ & 0,965 \\
$P_{8}$ & 0,109 & 0,978 & 0,149 \\
\hline
\end{tabular}

Fonte: Dados da pesquisa (utilização do SPSS).

Quanto aos testes relacionados ao número de componentes utilizados na análise, prevaleceram como componentes principais as variáveis $C D\left(\mathrm{P}_{4}\right)$ e GD $\left(\mathrm{P}_{5}\right)$, em segundo lugar a variável $\mathrm{DP}\left(\mathrm{P}_{8}\right)$ e na terceira posição a $\mathrm{DE}\left(\mathrm{P}_{7}\right)$.

$\mathrm{O}$ poder explicativo da variância total destes componentes foi considerado significativamente importante, de forma que cada variável destacada foi considerada para a formação do ranking de gestão fiscal dos municípios catarinenses estabelecido no quadro 2, cumprindo-se dessa forma o objetivo inicial do presente estudo em criar a hierarquização da gestão pública. 


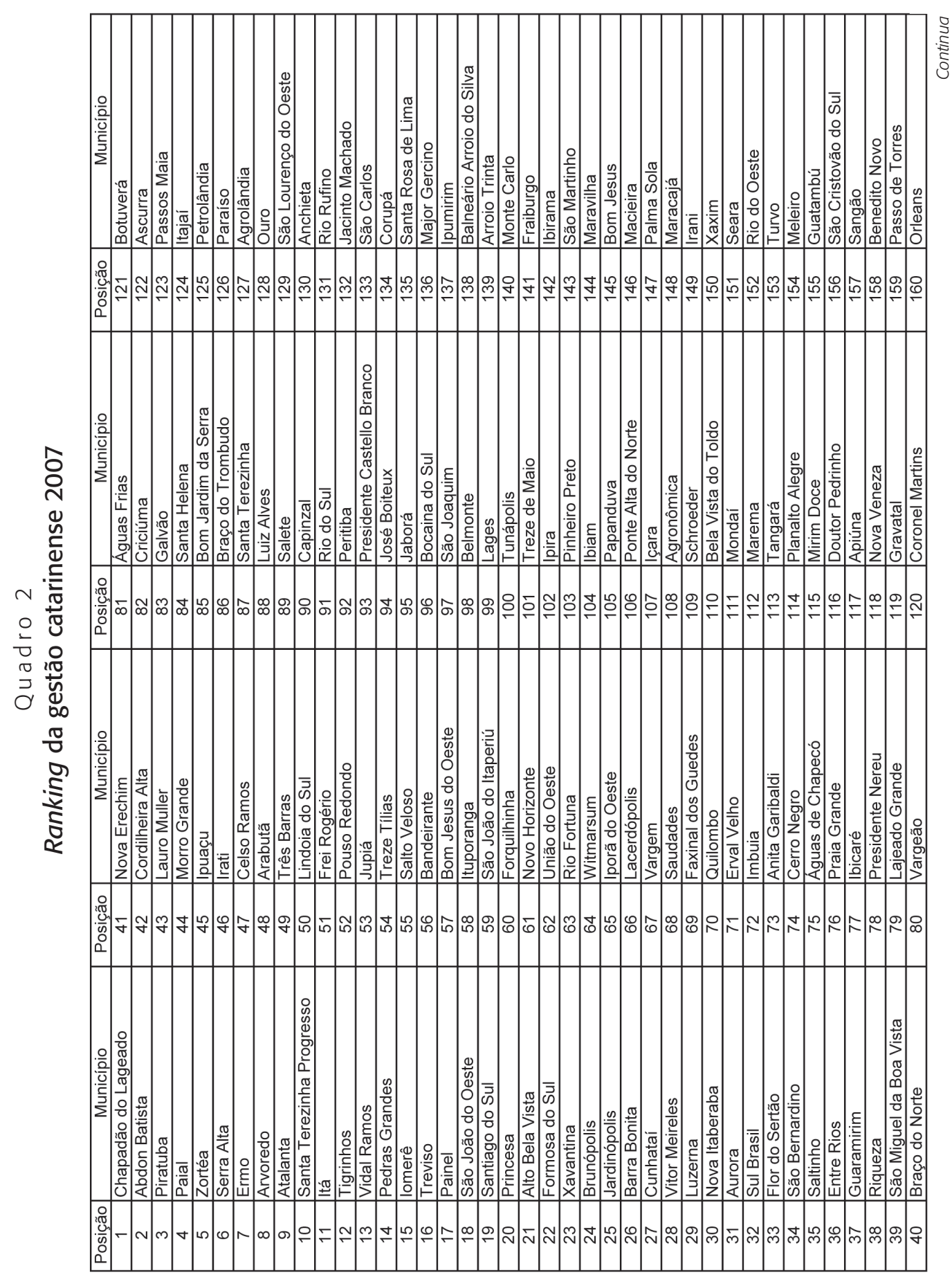

RAP - RIO DE JANEIRO 45(5):1425-443, SET./OUT. 2011 


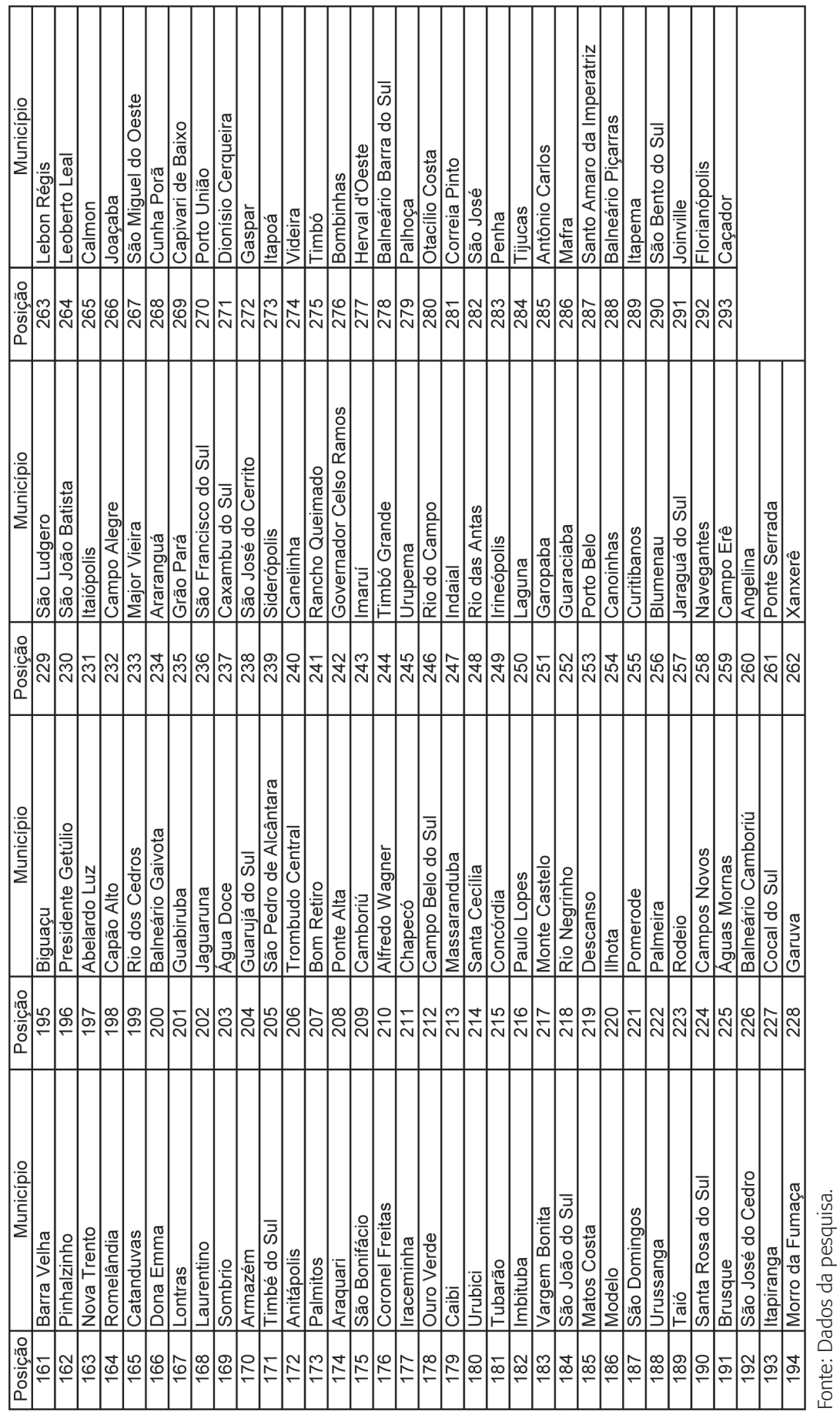

RAP - RIO DE JANEIRO 45(5): 1425-443, SET./OUT. 2011 
A partir do quadro formado é possível constituir análises em relação à classificação de cada município catarinense no ranking da gestão fiscal em 2007, porém optou-se por verificar os extremos da tabela.

A primeira análise do ranking diz respeito à presença, nas 10 primeiras colocações, de municípios com pouca expressão no cenário econômico estadual e pequenos em número de habitantes, não ultrapassando cinco mil habitantes por cidade, como os casos de Paial, com 1821 moradores, e Ermo, com 1843.

Esta classificação inicial é fruto do pequeno grau de endividamento, dos baixos gastos com despesas de pessoal e da aplicação mínima exigida em lei na área da educação.

Entretanto, ressalta-se que as análises efetuadas nas demonstrações contábeis dos municípios não consideraram o número de habitantes como variável de pesquisa.

Já no final do ranking, alguns municípios destacam-se de forma contrária por serem considerados grandes em movimentação econômica, arrecadação de tributos, diversificação de atividade e número de habitantes, como são os casos de Joinville, Florianópolis e São José.

A classificação desses municípios na parte final do ranking é justificada devido aos altos níveis de endividamento, mesmo apresentando bons índices de arrecadação.

\section{Considerações finais}

O presente artigo teve como objetivo demonstrar em que medida os índices de análise econômico-financeira podem ser empregados na administração pública, quando se pode estabelecer um ranking na gestão dos municípios catarinenses.

Pode-se afirmar que as dificuldades e o desinteresse da análise de balanços na área pública são frutos de um modelo contábil legalista aplicado há anos no setor, e também pelo lapso de tempo em que a contabilidade pública brasileira ficou estagnada. Diferente do que ocorre na área privada, na pública não se podem definir estruturalmente quais índices são mais utilizados, devido à falta de difusão do conhecimento, padrões ou utilização dos mesmos.

Porém, o resultado obtido nesta pesquisa revela a importância do emprego da análise de balanços na área pública, não apenas para atingir os objetivos do presente trabalho, mas como ferramenta a ser utilizada no cotidiano da administração pública, quer seja federal, estadual ou municipal. 
Dessa forma, poder-se-á conceber um cenário de independência da contabilidade no setor público para aplicar técnicas contábeis e não apenas orçamentárias, e como consequência disso, prover uma maior gestão nos gastos públicos.

A utilização do método estatístico não linear multivariado por meio da análise de componentes principais permitiu o exame conjunto dos índices empregados para a formação do ranking da gestão fiscal e serve como instrumento para outras análises gerenciais a serem empregadas nas demonstrações da área pública.

Assim, confirma-se também a importância quanto à evidenciação das contas públicas, pois além de ser uma obrigação do gestor público, é um misto de direito e dever dos cidadãos num país democrático de direito como o nosso, inclusive quanto à fiscalização dos atos de gestão dos administradores públicos.

Mesmo que haja muito a fazer para que a contabilidade sirva como autêntico instrumento de gerenciamento e accountability, como objeto precípuo, a contabilidade pública deve disponibilizar informações ao administrador público a fim de indicar o estado atual e planejar o futuro das entidades governamentais.

Como sugestão para futuras pesquisas, propõe-se o emprego deste estudo utilizando-se de outro método estatístico, bem como que seja aplicado em outros exercícios financeiros.

\section{Referências}

ANDRADE, Nilton de Aquino. Contabilidade pública gestão municipal. São Paulo: Atlas, 2002.

ANGÉLICO, João. Contabilidade pública. São Paulo: Atlas, 1990.

BABBIE, Earl. Métodos de pesquisas de survey. Belo Horizonte: Ed. UFMG, 1999.

BRASIL. Lei Federal no 4.320 de 17 de março de 1964. Brasília, DF: Senado, 1988.

BRASIL. Lei Complementar no 101 de 4 de maio de 2000: estabelece normas de finanças públicas voltadas para a responsabilidade fiscal e dá outras providências. CFC — Guia Contábil da Lei de Responsabilidade Fiscal: Brasília, DF: CFC, 2001.

CONSELHO FEDERAL DE CONTABILIDADE. NBC T 16 - Normas brasileiras de contabilidade aplicadas ao setor público - 16.1 - conceituação, objeto e campo de aplicação. Disponível em: <www.cfc.org.br/uparq/NBCT16_1.doc>. Acesso em: 2 dez. 2008. 
CONSELHO FEDERAL DE CONTABILIDADE. Resolução 1.133/2008, de 21 de novembro de 2008. Brasília. DF: Conselho Federal de Contabilidade, 2008.

FILHO, Antônio José. A importância do controle interno na administração pública. Revista Diversa, Parnaíba, v. 1, n. 1, p. 85-99, jan./jun. 2008.

GIL, Antônio Carlos. Técnicas de pesquisa em economia. 2. ed. São Paulo: Atlas, 1995. KOHAMA, Heilio. Balanços públicos: teoria e prática. São Paulo: Atlas, 1991.

KOHAMA, Heilio. Contabilidade pública: teoria e prática. 8. ed. São Paulo: Atlas, 2000.

LUCHESA, Cláudio Jose. Estudo da adequação dos índices da análise econômico-financeira às empresas florestais, utilizando métodos estatísticos multivariados. $225 \mathrm{f}$. Tese (doutorado em economia e política florestal) — Setor de Ciências Agrárias, Universidade Federal do Paraná, Curitiba, 2004.

MAROCO, João. Análise estatística com utilização do SPSS. Lisboa: Silabo, 2003.

MARTINS, Eliseu. Análise crítica de balanços. Parte 1. Boletim IOB. Temática Contábil e Balanços. Bol. 26. 2005.

MATARAZZO, Dante Carmine. Análise financeira de balanços. 5. ed. São Paulo: Atlas, 1998.

MATIAS-PEREIRA, José. Finanças públicas: a política orçamentária no Brasil. 3. ed. São Paulo: Atlas, 2006.

MEIRELLES, Hely Lopes. Direito administrativo brasileiro. 25. ed. São Paulo: Malheiros, 2000.

NACIMENTO, Edson Ronaldo. Gestão pública. São Paulo: Saraiva, 2006.

PIRES, Valdemir Aparecido. Sobre responsabilidade fiscal. Piracicaba: Unimep, 1999.

RICHARDSON, Roberto Jarry et al. Pesquisa social: métodos e técnicas. 3. ed. São Paulo: Atlas, 1999.

SECRETARIA DO TESOURO NACIONAL - STN. Sistema Finbra - Finanças do Brasil. Disponível em: <www.stn.gov.br> . Acesso em: 10 maio 2009.

SILVA, Lino Martins da. Contabilidade governamental: um enfoque administrativo. 7. ed. São Paulo: Atlas, 2004.

SLOMSKI, Valmor. Manual de contabilidade pública: um enfoque na contabilidade municipal. 2. ed. São Paulo: Atlas, 2003.

TRIBUNAL DE CONTAS DO ESTADO DE SANTA CATARINA — TCE/SC. Guia da Lei de responsabilidade fiscal. Florianópolis: TCE/SC, 2001. 